\title{
A Survey of the Field of Hazard and Disaster Studies
}

\author{
David E. Alexander \\ Institute for Risk and Disaster Reduction, University College London, London WC1E 6BT, UK
}

\begin{abstract}
This paper examines trends in the impacts of disasters at the world scale and proposes explanations for them. It is concluded that statistics on natural hazards are questionable, in that changes in recording methods have artificially inflated the number of disasters and the seriousness of their impacts. Next, the paper examines the symbolic interpretation of disasters at various scales of analysis in terms of human cultures. It further applies this approach to the analysis of natural hazards using information technology methods such as GIS (Geographic Information Systems). Returning to the global scale, deficiencies and inequalities in the world disaster relief system are considered. Thereafter, the paper investigates how global economic imbalances are thrown into sharp relief by catastrophes, with examples from the record of past earthquakes, landslides and floods. Finally, it considers the prospects for a major change in the direction of world policy on disasters and concludes that this will only occur if the international financial system is forced to adjust to a "super-disaster" event, which could possibly be seismic, volcanic or nuclear in origin.
\end{abstract}

Key words: Hazard, vulnerability, risk, culture, disaster, economic impacts, mitigation policies.

\section{Introduction}

In 1995, I was invited to write an introductory essay for a symposium on hazards [1]. In this work, I summarised the current state of play in this field. I noted that "at no time in history more than at the present has there been a wider gap between the expectations of people in societies with differing levels of economic development” [1]. The poorest countries have large amounts of unmitigated basic vulnerability, which means that disasters waste and destroy their fundamental assets. On a more positive note, I observed a gradual increase in training, information dissemination and the benign application of technology for disaster relief. However, I saw little sign that the gap between social and physical sciences would be bridged in a meaningful way that would lead to a holistic approach capable of explaining hazards and disasters. I also discussed the dual role of technology as a source of both vulnerability and mitigation.

On developing the ideas presented in that article at greater length in a book [2], I added that the world has

Corresponding author: David E. Alexander, Ph.D., professor, research fields: emergency planning and management, disaster risk reduction and earthquake hazards. E-mail: david.alexander@ucl.ac.uk. begun to change so fast that the fundamental theoretical basis of our attempts to explain and tackle hazards will need constantly to be re-evaluated. We still rely on theory that was formulated in the 1950s and 1960s to explain a world that, in significant measure, no longer exists. Some of the theory is good enough to endure [3, 4], much of it is not.

In the years that have passed since the 1995 article several attempts have been made to develop theoretical explanations of disaster [5-7]. Considerably more work needs to be done. Hence the present paper is a further attempt to identify and characterise recent changes in the world of hazards. Although the last dozen years have seen the continuous development and widespread diffusion of methodologies (for example GIS) that help us develop a better understanding of hazards, the expectations gap mentioned above has not closed. Despite the efforts of world bodies, donor countries and international charities, it has widened. Technology is still both the problem and the solution. But, as the following account argues, recent experiences have contributed some unsettling truths to the story of disasters. 
I begin, as in 1995, with an examination of disaster trends.

\section{Disaster Statistics, 1950-2012}

On average about 720 disasters and three new armed conflicts occur each year [8]. An "average” day would see two or three disasters in their emergency phases, 15-20 in their recovery periods, and about a dozen conflict-based emergencies in progress. Some of the conflict situations fall into the category of "complex emergencies” (situations of military conflict connected with economic and social breakdown), of which there are currently 25 [9]. Such intractable situations have generated at least 10 million international refugees and perhaps an equal number of internally displaced persons [10]. However, these statistics need to be seen in the light of longer-term trends. According to the Munich Reinsurance Corporation [11], over the period 1950-2000, the annual average number of disasters increased by two and a half times and the number of these that involved mass casualties went up by five times, as did the number of people affected by disaster. Losses attributed to disaster increased by fifteen times, and insurance repayments as a result of catastrophes went up 16.4 times.

Landslide disasters vividly illustrate this trend. According to data supplied by the Centre Research on the Epidemiology of Disasters at the Catholic University of Louvain, over the period 2000-2004, 110 mass movement catastrophes occurred, 33 of them in China and Indonesia which are particularly susceptible to this kind of event (as are Brazil, the Philippines and formerly Soviet central Asia). In contrast, only 20 landslide disasters were recorded over the entire decade of the 1950s.

Whereas, the 1989 Loma Prieta earthquake in California cost US \$12,000,000,000 (\$12 billion) in damages and other losses, it was followed only five years later at Northridge by an earthquake that cost three-four times as much, and in 1995 by the Hanshin-Awaji (Kobe, Japan) earthquake, that gave rise to losses totalling $\$ 131.5$ billion [12]. One scenario for the next major earthquake to strike the Tokyo metropolitan area suggests that it might be a modern repeat of the 1923 Kanto earthquake and ensuing urban firestorm. Although death tolls would probably not exceed 60,000, total economic losses could be reach US $\$ 2,700$ billion or half of the Japanese annual gross national product, in which property losses would account for at least $\$ 1,000$ billion [13]. With such events in mind, the mean curve for rising losses suggests that by the first disaster of 2020 they should become infinite. Something is clearly wrong with the way trends are calculated, but there are two sides to the story.

On the one hand, in confirmation of the last half-century's trends, if not entirely of the future ones, the populations of the main hazardous areas (notably seismic zones and coasts affected by hurricane-induced flooding) have grown substantially in size and urban density. Socio-economic inequality has also grown hugely, creating a vast global population of underprivileged people who are profoundly vulnerable to disaster: Indeed, disaster is a good description of the arduousness and precariousness of their daily lives [14]. In richer areas threatened by hazards, the level of investment in fixed capital has grown enormously while the populations are increasingly mobile, which places them in more situations of risk. Socio-economic networks are more complicated and variegated than they once were and there is now a greater tendency to take risks [15].

This trend is particularly evident on the peripheries of the world's largest and poorest cities: Caracas, Rio de Janeiro, Lima, Durban, Manila and so on. The poor are constrained to settle on the most unstable land. Hence, they are risk-takers by default. The loss of 30,000 lives when, on 16 December 1999, the barrios slums of Caracas were swept away by mudflows was only one event among many repeated disasters, albeit the largest of its kind [16].

On the other hand, global communications in the 1950s were such that many disastrous events went 
unrecorded outside the remote areas in which they occurred. Typically, in 1950, a landslide or earthquake that caused fatalities in the Hindu Kush of Afghanistan would not be widely reported in the international press unless the event had particular international repercussions. Moreover, in general only the direct effects in terms of losses and damage were taken into account, while the many collateral, subsidiary, secondary and consequent impacts went unrecorded. Nowadays, if an electronic transaction is delayed or does not take place, that is considered a loss. The global integration of production and commerce has led to extraordinary knock-on effects when disaster strikes any part of the economic system. Small wonder, therefore, that the toll of losses has apparently risen so steeply.

In summary, as the statistics for mortality, morbidity, population displacements and losses are highly variable from one year to another, trends depend heavily on the period of time over which they are averaged. This has the effect of making generalisations about this field unreliable. For example, annual death tolls in disaster appeared to fall from a mean of 75,000 in the early 1990s to one of 59,000 by 2003 [17], but the Asian tsunami of 26 December 2004, which affected ten countries over a vast area of the Indian Ocean basin, killed at least 230,000 people, equivalent to the running average for the previous four years. Likewise, the 53,000 deaths in the Kashmir earthquake of 8 October 2005 will have affected the mean. This is typical of the unevenness of trends in disaster death tolls and should warn us to be prepared for the effects of occasional cataclysmic events.

But what do those events mean in the modern world? The next section will examine them in terms of a new approach that considers the impact of technology on human cultures.

\section{Decoding the Symbolism of Disasters}

In a world increasingly dominated by information and communications technology, disaster has come to be associated with symbolism in the Jungian sense [18]. The meaning of calamity must therefore be deduced by interpreting the symbols, which requires an understanding of human cultural matrices [6]. Culture is an omnipresent phenomenon, but as we live in its embrace we find it difficult to define [19]. Moreover, it is not amenable to easy quantification-indeed, perhaps it can not be quantified in any meaningful way at all. Hence, let is consider what culture is in order to define what it means for our understanding of disaster.

Culture is not static, instead it undergoes continual metamorphosis. This consists of the transformation of inherited cultural traits and beliefs by cross-fertilisation with new cultural imperatives. Brislin [20] defined the former as emic concepts (i.e., specific to given cultures), while most of the latter are etic, i.e., generally present across diverse cultures. An etic component of culture is easily recognizable because it crosses diverse ethnic, religious and geographical settings. The ubiquitous soft drink advertising and associated international youth culture are an example of this, while in the field of disaster studies the so-called "disaster subcultures" [21] are another. An emic component is not easily transposed into other cultures. It usually has specific origins within the history of an individual population. Examples vary from ceremonies to propitiate the gods of hazardous places to specific perceptions of risk and locally-generated measures to reduce it.

While, to be fair, not all inherited traits are emic, the main driving force of the process of metamorphosis in the 21st century is the dominance of universal consumer culture and mass media-based etic cultural conditions.

A person's or a community's culture is thus like a set of Chinese boxes or Russian dolls: within each cultural container there is another. The sum of inherited traits and beliefs makes up the long term. It guides and conditions somewhat the accumulated traits and beliefs of a lifetime, which represent the cultural medium term. In western society, and increasingly elsewhere, etic 
consumer and mass-media culture form the short-term input (most of the exceptions are ideological ones, such as religious fundamentalism and radical terrorism). The new culture is absorbed into the old (Fig. 1). It is interpreted in the light of existing cultural references and the result is a form of cross fertilisation. In this process, context (particularly relating to migration and inter-ethnic mixing) determines whether local, regional, national or super-national (e.g., European) facets of culture dominate a person's interpretation of events. We are all both prisoners and beneficiaries of our cultures.

Despite impressions to the contrary [22], ideology does not enter into direct conflict with technology, even though it sometimes enjoys a parallel existence. In terrorist outrages, ideologically charged events--technology is scorned, subverted and employed, as was the case in the attacks on the United States in September 2001 [23]. Here, as elsewhere, there are signs in the cultural interpretation of disasters that the metamorphosis is often superficial: Peel away the consumerism, for example, disaster as spectacle and entertainment in the manner espoused by the mass media--and old attitudes are once again revealed, for instance, the superstitious interpretation of disasters as portents or indications of celestial disarray [24].
In addition to technology and ideology, a second dichotomy concerns the difference between learned and popular cultures [25]. In truth, the two are not quite separate from one another given that science, for example, is easily popularised. However, the wealth gap that so characterises the modern world leads increasingly to deprivation of learned culture, something that popular culture can not remedy. The old adage that knowledge is power is not quite accurate, but it is certainly true that lack of knowledge, i.e., ignorance-deprives people of the ability to manage hazards and risks [26].

In wealthy societies, one of the consequences of absorbing much etic consumer culture is a feeling of isolation from risk. It is increasingly recognized to be an illusion, and hence in intellectual circles we are entering a period of re-evaluation of very large events. However, in part this is being driven by neocatastrophism, a reaction to two centuries of scientific uniformitarianism [27], as well as millennialism, which yields some odd parallels with the intellectual milieu 1,000 years ago [2]. Yet it is also a sensible precaution when faced with an expanding population and an overburdened environment. Hence, for some people the sense of isolation from risk will turn out to be a cruel illusion,

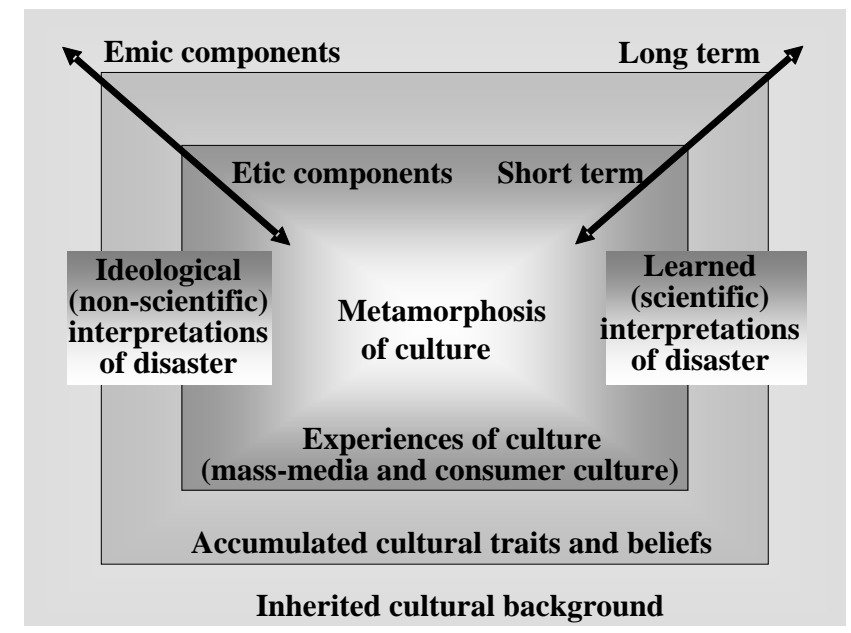

Fig. 1 Culture, cultural change and the interpretation of disasters. 
however well protected the majority are.

A second consequence of etic consumer culture is the "pipeline of sympathy", a tendency to donate to good causes when they are spectacularly publicised and ignore them when they are not, turning the aid-and-relief valve to the off position [28]. As a typical example, the aftermath of the Asian tsunami of 26 December 2004 overshadowed a critical drought, food shortage and security situation in Sub-Saharan Africa, which the world roundly ignored while it donated money to the tsunami relief effort in sums too copious to spend. Subsequently, the Kashmir earthquake of 8 October 2005 followed so closely upon Atlantic and Caribbean hurricanes, among other disasters, that the world community's first reaction was a massive attack of “donor fatigue”.

In the next section, I will apply some of the concepts developed above to the subject of the use of technology_in particular GIS methods-in applied natural hazard studies.

\section{Natural Hazards and the Information Technology Revolution}

At the beginning of the 1960s, the first faltering steps were taken to apply computer science to geological problems using huge, expensive mainframe computers (the IBM 360, for example) that had a computing power which is now vested in instruments that can be purchased for small sums of money and are compact enough to hold in one hand. Since those early days the development of semi-conductors, microchips and nano-transistors has created exponential growth in computing power. Moreover, the opposition to computer analysis which was then common has disappeared as the analysis itself has become more realistic, probing and useful. However, the problems have not gone away, they have simply mutated.

A classic paper by Quarantelli [29] has ably summarised the difficulties and dilemmas of perception associated with using technology to plan for and manage disasters. While he saw the information technology revolution as a development comparable to the invention of printing or television, Quarantelli added this telling comment [29]: “close inspection of technological development reveals that technology leads a double life, one which conforms to the intentions of designers and interests of power and another which contradicts them-proceeding behind the backs of their architects to yield unintended consequences and unanticipated possibilities.”

Three aspects of Quarantelli's analysis offer particular food for thought: The first is the difficulty of attributing an appropriate value to information when it is present in such copious amounts; Secondly, it follows from this that the current dominance of the mechanical aspects of technology over the social ones may restrict our ability to distinguish the relative importance of problems and the best strategies and techniques for solving them; Thirdly, as noted in the quotation above, there are the unintended consequences, which at best can complicate processes of analysis and at worst may invalidate them. In typical GIS analysis, for example, the results can depend heavily on the variables chosen, the order in which they are incorporated into the analysis and the relative weight they are assigned. The results in terms of, for instance, the hazardousness of a valley subject to landslides, can be subject to interpretations that vary widely with the sensitivity of output results [30].

Quarantelli observed that "the physical technology typically evolves ahead of the non-physical infrastructure”. The latter involves culture and perception. As Fig. 2 shows, the route to enlightenment leads us to make use of culture, perception and symbolism as we strive to decode images and make sense of information flows. A purely mechanical (or mechanistic) approach will not make this process efficient as it will obscure, though not cancel out, the cultural, perceptual and symbolic processes.

Contrary to popular belief, problems do not always propose themselves for solution, nor do they form a natural hierarchy waiting to be solved. What we regard 


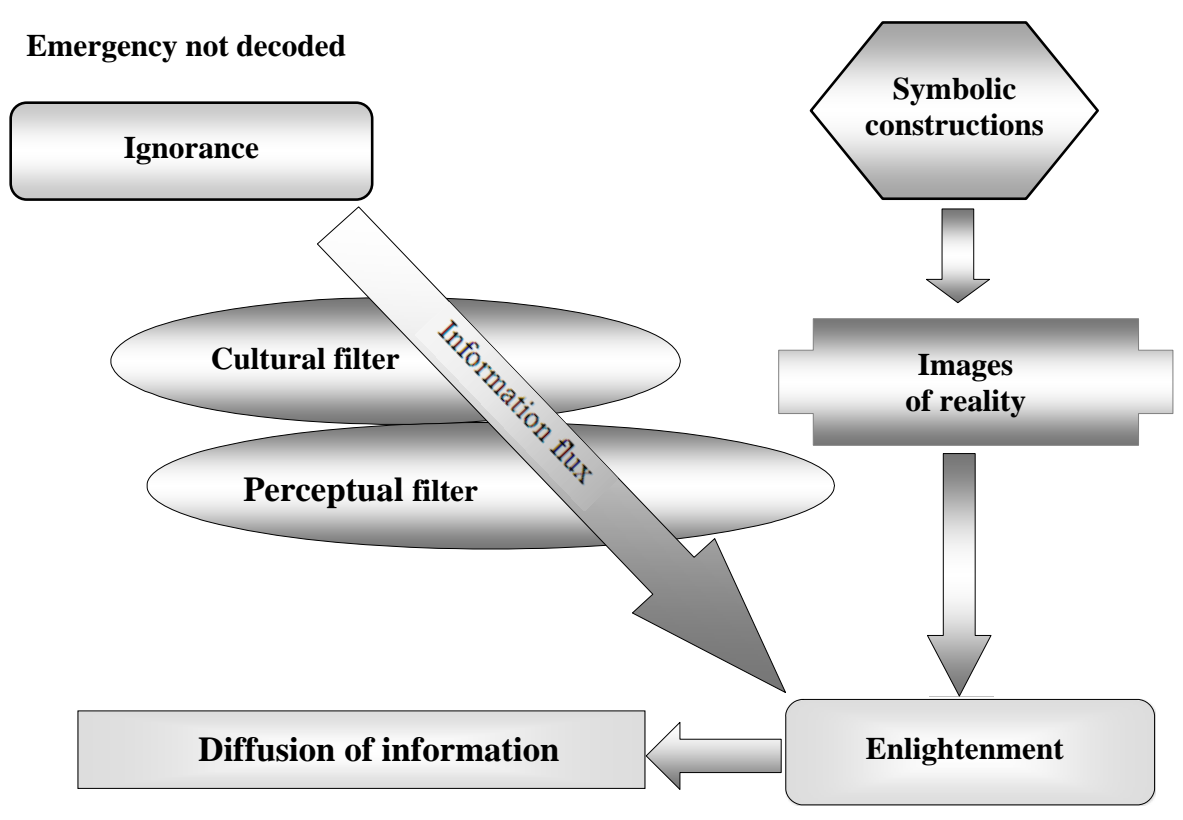

Emergency decoded

Fig. 2 The route to enlightenment by interpreting information.

as important or pressing depends on our priorities, which are influenced by culture, perception and consensus through discussion. As Quarantelli put it [29], "What is required for adequate handling of IT is a social infrastructure and cultural framework that will guide the behaviour of the users."

GIS is a very powerful means of automating the collection and comparison of geographical data. It therefore offers a good illustration of the need for more acute reasoning when designing research projects. GIS uses an overwhelmingly inductive methodology, which has the benefit of a high degree of flexibility but the drawback of low explanatory power. As with many other inductive methods, there is a strong risk that the tool will become more important than the results it is intended to produce. Hence, more effort may be expended on finding novel applications of GIS than on investigating whether they actually contribute much to hazard recognition and mitigation, other than accelerating the process.

GIS has undoubtedly speeded up, for example, the investigation of landslide susceptibility and geological mapping and has made them more efficient, but it has not necessarily advanced the conceptual side of that process since the times when hand calculations, pencils and squared paper were used. Its potential for investigating the significance of variables in terms of geology, environment and hazard management remains largely untapped.

In writing this I am not intending to be a Luddite. I am instead making a plea for careful evaluation of the bases of investigation. We need to recognize that cultural and social factors are inherent in choosing a problem to solve and a methodology to arrive at the solution. In this respect, we are moving all too slowly towards a more holistic approach to science in general and hazard studies in particular. In the future, the philosophy behind these endeavours should be non-disciplinary: let the problem, not the discipline, determine the questions which we ask, the mode of analysis we choose and all the other ways in which a solution will be sought.

In synthesis, we should not attempt to develop technologies such as GIS without, first, a good idea of 
how we can profitably use them, and secondly acquiring an awareness of their cultural significance. Simply because such methodologies involve measurement and calculation it does not mean that they are neutral in cultural terms, for many choices have nevertheless to be made every time a research project is designed. Conversely, attempts to reduce culture to similarly mechanistic levels of measurement have yielded disappointing results [31].

It may be that research needs to begin with the application of moral philosophy rather than technical criteria [32]: for whose benefit is the research conducted, and what indeed are the tangible benefits?

\section{The Consequences of Disaster and the Failure to Mitigate Them}

Disasters constantly reveal the tragic lack of preparedness in vulnerable communities all over the world. Rather than generating new knowledge, there is a chronic need to apply the existing fruits of research and development. If there is a demand for more research, it should focus on analysing why existing knowledge is not being applied to the mitigation of disaster risks in specific situations. In this respect, poverty, conflict and political manipulation are the three main factors that inhibit change [33].

The main consequences of failure to prepare are avoidable deaths and losses. For example, in the 1986, El Salvador earthquake four hospitals collapsed: again in the January 2001 El Salvador earthquake four hospitals collapsed. This suggests that virtually no progress had been made in the intervening 15 years in safeguarding these critical facilities [34].

A further set of consequences can be found in the inefficiency of the world disaster aid system. When a major catastrophe strikes, the international publicity given to it and the consequent groundswell of public opinion may induce up to 70 countries to participate in the relief effort by donating goods, money, manpower or expertise [28]. However, only five countries (all in Scandinavia and northern Europe) have provided international aid worth $0.7 \%$ of their gross national incomes, as pledged by all of the donor nations at the UN Conference on Environment and Development in 1992. Much disaster aid is tied to political alliances, the use of donor countries' resources (a form of aid recycling), and promises of assistance that are only partially maintained [35]. In some instances associated with the Asian tsunami of December 2004, only one fifth of the aid that was pledged was actually supplied.

Significantly, in major catastrophes disaster, assistance is supplied internationally rather than generated locally. The same sorts of aid were air freighted in the same way from Toronto to San Salvador after both the 1986 and 2001 earthquakes, again an indication of failure to prepare [34]. Critical aid may arrive too late to be useful, but this may not stop it from being very costly. Some 1,200 foreign rescuers converged on Armenia after the December 1988 earthquake. At least 2,200 made their way to Izmit after the August 1999 earthquake in Turkey and 1,600 arrived in Bam, Iran, within five days of the December 2003 earthquake. In Armenia only 60 people were saved by the foreign USAR (urban search and rescue) teams and in Bam the total was 30. In the latter case the British rescue team, with 57 members, saved no one from death under the rubble. In the Izmit case, 2,300 Turkish doctors and innumerable Turkish rescuers had already made their way to the disaster area when the foreigners started to arrive [21].

The totals of victims saved are so low, not because the international rescue teams lack expertise (though they may well lack critical resources that cannot be transported into the field, such as baulks of wood for shoring up tunnels into the rubble), but because they simply arrive too late to be of much use. The vast majority of victims extracted alive from under the rubble of collapsed buildings are brought out within 6-8 hours of the impact, after which survival rates tail off rapidly [36], yet this is far too short a period for international teams to arrive, register their presence, set up base camps and deploy themselves. Hence, the cost 
of rescues by foreign USAR teams averages something like US \$1 million per life saved: with well-trained and well-equipped teams of local volunteers it would diminish to 50 cents to one dollar per life saved [37].

Moreover, after the Bam earthquake of 26 December 2003, 12 field hospitals were deployed. The US field hospital treated 777 patients, but not one of them had injuries that directly resulted from the earthquake. The field hospitals cost an average of about $\$ 1$ million each to deploy, the total sum of money involved amounted to $44 \%$ of the cost of completely rebuilding Bam's two collapsed hospitals, about $\$ 27.5$ million. During the early stages of the emergency most seriously injured victims were treated in Bam's airport terminal, or indeed on the tarmac outside, before being airlifted to Tehran for further treatment. Field hospitals can fulfil a useful role in providing back-up care, but there is no substitute for making the regular local hospitals resistant to disaster [38]. The same moral obligations apply to another pressing problem regarding critical facilities: the safety of the world's schools. In the Boumerdes earthquake of 2003 in Algeria, 103 schools collapsed completely, 753 were seriously damaged and 2,160 were damaged or compromised in other ways [39]. Far worse, early indications from the October 2005 Kashmir earthquake suggest that there might have been 32,000 children deaths in the collapse of 140,000 schools. There is a universal moral imperative that disaster victims should have a right to emergency medical treatment and children should have a right not only to be educated, but to be educated in safety [40].

A significant component of the solution to the schools and hospitals problem may be to get the world's leaders to focus their attention on it until there is a more general acceptance that a moral imperative that exists in the same league as the need to reduce the impacts of global climate change. The solutions to the problem of wasteful international transfers of aid and manpower are firstly to stockpile aid in locations of predictable future need and secondly to organise the transfer of technology and expertise to such places.
This could be achieved by, for example, setting up USAR (urban search and rescue) brigades in countries and places that have a particular need for them, ensuring that they are adequately funded and equipped, and organising twinning arrangements with established USAR units from the donor countries.

Although there are fewer casualties in the largest landslide disasters than in major earthquakes, they can occasionally be similar in terms of emergency responses. As in Armenia and Bam, huge numbers of rescuers converged on the small Welsh town of Aberfan when, on 21 October 1966, 116 children and 28 adults were crushed to death by a mudflow that came from an artificial hill of coal mining debris which collapsed spontaneously onto two schools and a residential area. Had this absurd risk situation occurred 30 years later, GIS would probably have been used to map hazard and vulnerability and indicate areas of high pore-water pressure and low factor of safety. However, one can not negate the fact that the disaster at Aberfan was caused, not by failure to use sophisticated analytical techniques, but by a more elemental form of negligence: the post-disaster enquiry [41] was easily able to establish that tipping vast amounts of loose shale at its angle of repose onto an active spring located beside a residential area would inevitably lead to tragedy. The lesson of this is that technology is powerless to prevent disaster when the root cause is a defect of institutional culture.

\section{Large Disasters in the Future}

On 26 December 2004, exactly one year after the Bam earthquake had killed 26,500 people in Iran, nine or ten times as many were annihilated in the ten Asian countries affected by the Indonesian earthquake and tsunami (given that many people were washed out to sea by the waves, the exact death toll will never be known). Although the deaths in the tsunami were only about one third as many as in the worst natural disaster on record (the Shensi earthquake of 1556 in China), they were exceptional by modern standards, and so was 
the extent of damage and suffering. Two questions come to mind in connection with this latter-day anomaly.

First, what is the potential for a super-disaster? On 11 September 2001, 18 terrorists perpetrated on New York, Washington DC and Pennsylvania the worst and most spectacular outrage of all modern terrorism. Months before that fateful day, a debate had already begun in the United States regarding what magnitude of disaster we should prepare for Ref. [42]. Throughout the world, emergency plans are usually tailored to the sort of event that has a moderate or high probability of occurring over the life of the plan, which is probably about a decade. However, the death toll in a major destructive earthquake with epicentre near to Tehran or Istanbul could, it is estimated, cause between 300,000 and one and a half million deaths in each case [43]. Rarer but even more destructive, asteroid impacts upon the earth have an estimated frequency of once in half a million years, and super-volcanic eruptions (of which the geological evidence exists for 31 examples) have a probable average frequency of once in 100,000 years [44]. The last super-eruption occurred at Toba in Sumatra 74,000 years ago. Perhaps it is inappropriate to tie up scarce resources in preparing for contingencies of very low probability. However, such infrequent events pose an impossible planning dilemma, as if they were to occur they would have to be faced up to with every available resource.

The second question concerns what kind and magnitude of disaster impact would be capable of forcing a change in the international community's attitude to disasters. Despite many pious words spoken by world leaders after each new catastrophe, no event so far has led to a change for the better in the global counter-disaster strategy. The nearest thing to such a change has been the rise of homeland security in response to the terrorism threat after the events of 11 September 2001 [45]. The lessons of warfare and genocide are that the international economic system is indifferent to mass loss of life but is unlikely to shrug off a major financial loss. This hypothesis deserves further explanation.

\section{Counter-Disaster Policies and Economic Imbalance}

The collapse of the World Trade Centre in New York is estimated to have cost US $\$ 87$ billion. In contrast, monetary losses in the Asian tsunami of 26 December 2004 have been estimated at only US \$14 billion. Neither sum is sufficient to stimulate a major change of outlook. The same is probably even true of the \$200 billion losses in Hurricanes Katrina and Rita on the US Gulf Coast in the summer of 2005, despite the contemporary impact of these disasters on domestic gasoline prices. However, the economic storm clouds are gathering. Only about $20 \%$ of losses are covered by the insurance and reinsurance market, and there is a lack of capital to finance the underwriting of catastrophe risks. Despite this, the proportion of disaster losses that are insured continues to grow in line with the demand for policies [46]. The Tokyo earthquake scenario described above may, as some commentators have suggested, inflate losses by up to three times $[47,48]$, but whatever the reality may turn out to be, it points to the likelihood of a catastrophe that will change the course of economic history.

Pace Clausewitz, but as with politics and war, so disasters can be viewed as economics carried on by other means [49]. Whatever the sum total of human suffering it induced, the Asian tsunami of 2004 was not sufficiently costly to shake the world community out of its laissez faire. However, the knock-on effects upon world financial markets of a repeat of the 1923 Kanto earthquake would probably be enough to stimulate a radical rethink of the global strategy for reducing the risks of disaster and amortising the impacts. If not a major earthquake, a huge volcanic eruption or a major radiation contamination incident could conceivably have the same effect, though it very much depends on which geographical area receives the damage. 
In the short- to medium-term future, insurance will not be able to find enough capital to pay for disaster losses but in this neoliberal age governments will be unwilling to indemnify citizens as lavishly as they have done in the past. In the current world climate, there is a lack of opportunity to transfer financial resources to those in need through taxation and redistribution of wealth: such a "Robin Hood" approach to disasters is termed "forgiveness money", as it is seen as reducing the incentive for people autonomously to reduce the risks they assume. As such an attitude takes no account of situations in which chronic risk-taking is a matter of necessity, in the future poverty and vulnerability will define ever more closely the areas of major risk [50]. Poverty and vulnerability are not synonyms, but disaster is one agent through which the latter will be ever more closely linked to the former. At present the evidence on whether this will lead to a resumption of rises in death tolls is equivocal and no prediction can be made [51].

Over the last 35 years of uneven economic development, the world has become progressively more polarised between rich and poor societies [52]. In wealthy countries, disasters now kill only one seventh as many people as in poor countries, but in terms of monetary losses and quantified damage they cost nearly 12 times as much. The Asian tsunami of December 2004 ably highlighted this dichotomy. The event was anomalous, in that large numbers of foreign citizens were killed and injured while on vacation at the beaches of much poorer countries than the ones they came from. After the disaster, the governments of Western European and Scandinavian countries effectively exported their national health systems to the disaster area for the benefit of their injured citizens. Consular officials acted like governments in exile, but what was the level of care for indigenous people in the same places? Even within the donor countries the dichotomy of wealth is easily observed: for instance, on the western periphery of Rome one side of the railway tracks is home to the pleasant and comfortable modern office block of the UN's World Food Programme, while on the other side are the precarious scrap-wood dwellings of the "extracommunitaries", as poor immigrants to the European Union are locally known. Likewise, a study by Ben Wisner revealed that homeless vagrants are completely ignored by the disaster preparedness system in Tokyo [53].

In the 1890s, the US Army Corps of Engineers began a programme of dredging, levée-building, canalising and other structural modifications on the Mississippi River that was to last for almost a century. The outcome of it was, in 1993, the basin's largest flood on record, which in some places lasted for two and a half months [54]. Structural engineering work does not give $100 \%$ protection and can worsen the impact of a disaster when it fails (in this case by helping impound floodwaters on the floodplain behind the defences). The lesson is that failures of structural protection will be ever more costly and spectacular until an adequate transition is made to a balanced approach which relies on a mixture of engineering and planning precepts. Research in Bangladesh suggests that this could be beneficial to local communities in low-income areas if it utilises a social approach which takes account of local aspirations and finely-honed indigenous coping mechanisms wherever it is worth preserving such attributes [55]. The 20-year debate on the Bangladesh Flood Action Plan has shown that the worst that could happen is to constrain poor countries to go through the same sort of painful evolution of structural followed by planning measures that the Mississippi basin went through [56].

\section{Conclusions}

In synthesis, it is likely that the relentless rise in the cost of disasters and the corresponding aggravation of mortality risks will continue until change is catalysed by a significant enough event, perhaps a huge earthquake or volcanic eruption, or a major contamination episode. When it does, the world financial system will be reorganised to tackle disasters 
more effectively using properly programmed vulnerability reduction: it is a question of the utilisation of research, the accretion of willpower and the stimulation of a desire to organise matters well. Glimmerings of this change were apparent in the international aid conferences and summits that took place in the wake of the Asian tsunami of December 2004, but the impact was simply not large enough to have the full catalytic effect. While the world waits for such a change, there will be a slow increase in the professionalism of workers in civil protection. One hopes that it will be matched by sufficiently constant political attention and funding to enable the momentum to be kept up.

Currently, it is absurd but true that though we do not permit surgical operations to be carried out by amateurs, we allow mass-casualty disasters to be managed by people without qualifications. As emergency preparedness gradually turns into a fully fledged profession, education and training will become more fundamental, more systematic and a sine qua non of both management efforts after disaster and risk reduction initiatives before it. That is a very positive development, but the real challenge of 21st century in this field is to involve the general public in hazardous areas to take more responsibility for its own safety. Disaster reduction needs qualified experts, but the task is too great to be achieved by salaried workers alone. In the 2000s, we must democratise disaster: there are too many stakeholders to do otherwise.

\section{Acknowledgments}

The author thanks Prof. Fausto Marincioni of the Marche Polytechnic University, Italy, for helpful comments on a draft of this paper.

\section{References}

[1] D.E. Alexander, A Survey of the Field of Natural Hazards and Disaster Studies, in: A. Carrara, F. Guzzetti, (Eds.), Geographical Information Systems in Assessing Natural Hazards, Kluwer Academic Publishers, Dordrecht, 1995, pp. 1-19.

[2] D.E. Alexander, Confronting Catastrophe: New
Perspectives on Natural Disasters, Terra Publishing and Oxford University Press, UK and New York, 2000, pp. 129-131.

[3] A.H. Barton, Disaster and Collective Stress, in: R.W. Perry, E.L. Quarantelli (Eds.), What is a Disaster? New Answers to Old Questions, Xlibris Press, Philadelphia, 2005, pp. 100-129.

[4] I. Burton, R.W. Kates, G.F. White, The Environment as Hazard, 2nd ed., Guilford Press, New York, 1993.

[5] D.E. Alexander, The study of natural disasters, 1977-1997: Some reflections on a changing field of knowledge, Disasters 21 (4) (1997) 284-305.

[6] D.E. Alexander, An Interpretation of Disaster in Terms of Changes in Culture, Society and International Relations, in: R.W. Perry, E.L. Quarantelli (Eds.), What Is a Disaster? New Answers to Old Questions, Xlibris Press, Philadelphia, 2005, pp. 1-15.

[7] M. Pelling, Natural Disasters and Development in a Globalizing World, Routledge, London, 2003.

[8] World Disasters Report: Focus on Information in Disasters, IFRC (International Federation of Red Cross and Red Crescent Societies), Geneva, 2005.

[9] ReliefWeb, www.reliefweb.int (accessed Jan. 1, 2013).

[10] P. White, Special issue on complex political emergencies, Disasters 24 (4) (2000) 288-290.

[11] Topics, Annual Review: Natural Catastrophes 2001, Munich Re Group, Munich, 2002.

[12] L.S. Chan, Y. Chen, Q. Chen, L. Chen, J. Liu, W. Dong, et al., Assessment of global seismic loss based on macroeconomic indicators, Natural Hazards 17 (3) (1998) 269-283.

[13] What if the 1923 Earthquake Strikes Again? A Five-Prefecture Tokyo Region Scenario, RMS (Risk Management Solutions), Inc., Menlo Park, California, 1995.

[14] M. Duffield, The symphony of the damned: Racial discourse, complex political emergencies and humanitarian aid, Disasters 20 (3) (1996) 173-193.

[15] M.J. Cohen, Risk in the Modern Age: Social Theory, Science and Environmental Decision-Making, Palgrave MacMillan, London, 2000.

[16] H. Brandes, The Venezuela flash floods and debris flows of 15-16 December 1999, Landslide News 13 (2000) 5-7.

[17] H.C. Wilson, Editorial, Disaster Prevention and Management 14 (1) (2005) 1-5.

[18] J. Kroll-Smith, S.R. Couch, What is disaster? An ecological-symbolic approach to resolving the definitional debate, International Journal of Mass Emergencies and Disasters 9 (3) (1991) 355-366.

[19] C.J. Glacken, Traces on the Rhodian Shore: Nature and Culture in Western Thought from Ancient Times to the End of the Eighteenth Century, University of California Press, Berkeley and Los Angeles, 1967. 
[20] R.W. Brislin, Cross-Cultural Research Methods, in: I. Altman, A. Rapoport, J.F. Wohlwill (Eds.), Human Behavior and Environment: Advances in Theory and Research, Vol. 4: Environment and Culture, Plenum, New York, 1980, pp. 47-82.

[21] H. Granot, Disaster subcultures, Disaster Prevention and Management 5 (4) (1996) 36-40.

[22] S.P. Huntington, The Clash of Civilizations and the Remaking of World Order, Touchstone Books, Carmichael, California, 1996.

[23] C. Calhoun, P. Price, A. Timmer, Understanding September 11, The New Press, New York, 2002.

[24] D.B. Vitaliano, Legends of the Earth: Their Geologic Origins, Indiana University Press, Bloomington, Indiana, 1973.

[25] S.R. Couch, The cultural scene of disasters: Conceptualizing the field of disasters and popular culture, International Journal of Mass Emergencies and Disasters 18 (1) (2000) 21-38.

[26] G.F. White, R.W. Kates, I. Burton, Knowing better and losing even more: The use of knowledge in hazards management, Global Environmental Change Part B: Environmental Hazards 3 (3-4) (2001) 81-92.

[27] G.H. Dury, Neocatastrophism? A further look, Progress in Physical Geography 4 (3) (1980) 391-413.

[28] J. Borton, Recent trends in the international relief system, Disasters 17 (3) (1993) 187-201.

[29] E.L. Quarantelli, Problematical aspects of the information/communication revolution for disaster planning and research: Ten non-technical issues and questions, Disaster Prevention and Management 6 (2) (1997) 94-106.

[30] F. Ardizzone, M. Cardinali, A. Carrara, F. Guzzetti, P. Reichenbach, Uncertainty and errors in landslide mapping and landslide hazard assessment, Natural Hazards and Earth System Sciences 2 (1-2) (2002) 3-14.

[31] R. Palm, Urban earthquake hazards: The impact of culture on perceived risk and response in the USA and Japan, Applied Geography 18 (1) (1998) 35-46.

[32] T. Beatley, Towards a moral philosophy of natural disaster mitigation, International Journal of Mass Emergencies and Disasters 7 (1) (1989) 5-32.

[33] J. Macrae, N. Leader, Shifting Sands: The Search for "Coherence" between Political and Humanitarian Responses to Complex Emergencies, Humanitarian Policy Group report No. 8, Overseas Development Institute, London, 2000.

[34] B. Wisner, Risk and the neoliberal state: Why post-Mitch lessons didn't reduce El Salvador's earthquake losses, Disasters 25 (3) (2001) 251-268.

[35] M. Buchanan-Smith, Financing International Humanitarian Action: A Review of Key Trends,
Humanitarian Policy Group Briefing Paper No. 4, Overseas Development Institute, London, 2002.

[36] R.S. Olson, R.A. Olson, Urban heavy rescue, Earthquake Spectra 3 (4) (1987) 645-658.

[37] S. Briceño, Personal Communication, UN International Strategy for Disaster Reduction, 2005.

[38] PAHO (Pan American Health Organization), PAHO guidelines for the use of foreign field hospitals in the aftermath of sudden-impact disaster, Prehospital and Disaster Medicine 18 (4) (2003) 278-290.

[39] The Boumerdes, Algeria, Earthquake of May 21, 2003, EERI (Earthquake Engineering Research Institute), San Francisco, 2004.

[40] B. Wisner, I. Kelman, T. Monk, J.K. Bothara, D. Alexander, A.M. Dixit, et al., School Seismic Safety: Falling between the Cracks?, in: C. Rodrigue, E. Rovai, (Eds.), Earthquakes, Routledge Hazards and Disasters Series, Routledge, London, 2005.

[41] Report of the Tribunal Appointed to Inquire into the Disaster at Aberfan on October 21st, 1966, HMSO, Aberfan Tribunal, London, 1967.

[42] D.A. McEntire, A. Myers, Preparing communities for disasters: Issues and processes for government readiness, Disaster Prevention and Management 13 (2) (2004) 140-152.

[43] F.A. Nateghi, Earthquake scenario for the mega-city of Tehran, Disaster Prevention and Management 10 (2) (2001) 95-100.

[44] W. McGuire, I. Mason, C. Kilburn, Natural Hazards and Environmental Change, Arnold, London, 2002.

[45] A.D. Beresford, Homeland security as an American ideology: Implications for U.S. policy and action, Journal of Homeland Security and Emergency Management 1 (3) (2004) 1-301, http://www.bepress.com/jhsem/vol1/ iss3/301 (accessed Jan. 1, 2013).

[46] H. Kunreuther, R.J. Roth, Paying the Price: The Status and Role of Insurance against Natural Disasters in the United States, National Academy Press, Washington D.C., 1998.

[47] H.C. Shah, Scientific Profiles of the "Big One”, Disaster Research 179 and Natural Hazards Observer (November 1995), Natural Hazards Center, University of Colorado, Boulder, Colorado, 1995.

[48] J.H. Wiggins, A Reply to "Scientific Profiles of the "Big One”,', Disaster Research 181, Natural Hazards Center, University of Colorado, Boulder, Colorado, 1996.

[49] M.H. Atmor, Politicisation of humanitarian aid and its consequences for Afghans, Disasters 25 (4) (2001) 321-330.

[50] G. Bankoff, Vulnerability as a measure of change in society, International Journal of Mass Emergencies and Disasters 21 (2) (2003) 5-30. 
[51] J. Birkmann, Measuring vulnerability and coping capacity, Working Paper, United Nations University Institute for Environment and Human Security, Bonn, Germany, 2005.

[52] P. Blaikie, T. Cannon, I. Davis, B. Wisner, At Risk: Natural Hazards, People's Vulnerability and Disasters, 2nd ed., Routledge, London, 2002.

[53] B. Wisner, Marginality and vulnerability: Why the homeless of Tokyo don't “count” in disaster preparations,
Applied Geography 18 (1) (1998) 25-34.

[54] M.F. Myers, G.F. White, The challenge of the Mississippi flood, Environment 35 (10) (1993) 6-35.

[55] D. Hutton, C.E. Haque, Patterns of coping and adaptation among erosion-induced displaces in Bangladesh: Implications for hazard analysis and mitigation, Natural Hazards 29 (3) (2003) 405-424.

[56] M.M.Q. Mirza, A. Dixit, A. Nishat, Flood Problem and Management in South Asia, Kluwer, Dordrecht, 2002. 